\title{
Comunicación
}

\section{EVALUACIÓN CONSTANTE DEL VIRUS DE LA ENFERMEDAD DE NEWCASTLE EN AVES SILVESTRES DE LALAGUNAALBUFERA DE MEDIO MUNDO}

\author{
Surveillance of Newcastle Disease Virus in Wild Birds at Albufera de Medio \\ Mundo Lagoon
}

\section{Luis Mendoza R. ${ }^{1}$, Eliana Icochea D. ${ }^{1,3}$, Armando González Z. ${ }^{2}$, Rosa González V. ${ }^{1}$}

\section{RESUMIEN}

\begin{abstract}
El estudio evaluó la presencia del virus de la Enfermedad de Newcastle en la laguna Albufera de Medio Mundo, situada al norte de Lima, y habitada por diversas especies de aves silvestres y migratorias. Se realizaron tres etapas de muestreo, de 6 semanas cada etapa, obteniéndose 900 muestras de heces frescas de 11 especies de aves silvestres. Las muestras se inocularon en huevos embrionados libres de patógenos específicos (SPF) de 10 días de edad para lograr el aislamiento viral. Se evaluó la actividad aglutinante del fluido alantoideo de los huevos embrionados obteniéndose resultados negativos en todas las muestras. Se calculó una prevalencia media de $0.1 \%$ y una distribución de 0.002 a $0.4 \%$ por medio de la simulación beta. La prevalencia encontrada fue muy baja para considerar a estas aves como una posible fuente de infección hacia las aves domésticas.
\end{abstract}

Palabras clave: virus de la enfermedad de Newcastle, aves silvestres

\section{Abstract}

The study evaluated the presence of the Newcastle disease virus in the Albufera de Medio Mundo lagoon, situated north of Lima. The lagoon is inhabited for various wild migrant bird species. Three sampling periods were conducted of six weeks each, colleting 900 fresh fecal samples from 11 species. Samples were inoculated in specific-pathogen free (SPF) embryonated eggs of 10 days of age for isolation of the virus. The hemagglutinant activity of the allantoic fluid showed negative results in all samples. The estimated prevalence calculated through a beta simulation was $0.1 \%$ with a distribution between 0.002 and $0.4 \%$. The prevalence was too low for considering these birds as a possible source of infection toward domestic birds.

Key words: Newcastle disease virus, wild birds

\footnotetext{
${ }^{1}$ Laboratorio de Patología Aviar, ${ }^{2}$ Laboratorio de Medicina Veterinaria Preventiva, Facultad de Medicina Veterinaria, Universidad Nacional Mayor de San Marcos, Lima

${ }^{3}$ E-mail: eliana.icochea@gmail.com
} 
La enfermedad de Newcastle (ENC), enfermedad de declaración obligatoria a la OIE, es una de las infecciones en aves que causa mayor mortalidad. El contacto directo con aves silvestres portadoras y la transmisión por sus heces hacen posible la infección a las aves de granjas comerciales.

Se ha realizado diversos estudios en aves silvestres en el Perú (Icochea, 2007), no habiéndose encontrado anticuerpos contra el virus de la enfermedad de Newcastle en aves columbiformes (Eupelia cruziana “Tórtolas" y Columbia livia "Palomas silvestres”). Además, se realizaron exámenes serológicos en aves del orden Psittaciformes mantenidas en cautiverio en el Zoológico Parque de las Leyendas de Lima (Shimabukuro, 2000) y en aves paseriformes capturadas de su hábitat natural en la provincia de Chancay (Chang, 1998) con resultados igualmente negativos.

La enfermedad de Newcastle, entre 1987 y 1992 no representó mayor problema para la avicultura peruana, pero a partir de 1994 empezaron a suscitarse casos violentos de la enfermedad que comprometieron planteles de aves comerciales, principalmente con criadores de aves de pelea que no vacunaban contra la enfermedad de Newcastle. Estas cepas fueron identificadas en el Laboratorio Central Veterinario de Weybrydge, Gran Bretaña, como cepas velogénicas viscerotrópicas de alta patogenicidad (Chang, 1998).

En la actualidad, la enfermedad se encuentra presente en el país, habiendo ocurrido brotes de importancia en Moquegua en septiembre de 2002 (Resolución Directoral No 051-2002-AG-SENASA-MOQUEGUA) y en el distrito de Villa María del Triunfo, Lima, en febrero de 2003 (Resolución Directoral N${ }^{\circ} 63-2003-A G-S E N A S A ~ L I M A-$ CALLAO). Asimismo, estudios en gallos de pelea y gallinas de crianza casera, demostraron que la ENC en el Perú tiene una incidencia del 5\% (Ferrer 2002).
Se cree que las aves silvestres y otros animales exóticos han contribuido a la diseminación de la enfermedad, pero hasta el momento no ha sido totalmente evaluado su rol (Jordan, 1990). El presente estudio se realizó para determinar si las aves que habitan en los alrededores de la laguna Albufera de Medio Mundo se encuentran infectadas con APMV-1, y así, contribuir al control y erradicación de la ENC en el país.

Se trabajó con aves silvestres y migratorias que habitan la laguna Albufera de Medio Mundo. La laguna se ubica muy cerca del mar, en el distrito de Vegueta, provincia de Huaura, Lima. Las principales aves en la zona son el Cormorán, Pelícano peruano, Ostrero americano, Rayador, Playerito blanco, Gaviota dominicana, Gaviota gris, Zarapito, Pato andino, Garza blanca chica, y Garza blanca grande.

Al no existir datos sobre el número poblacional, se empleó la fórmula para determinar el tamaño muestral de poblaciones infinitas, dando como resultado 298 muestras. El muestreo se dividió en tres periodos, cada uno de seis semanas. Se colectaron 300 muestras por periodo y un total de 900 muestras de 11 especies de aves. El procesamiento de las muestras se realizó en el Laboratorio de Patología Aviar de la Facultad de Medicina Veterinaria de la Universidad Nacional Mayor de San Marcos, Lima.

Las muestras de heces frescas se colectaron con hisopos estériles. Se colectaron a primera hora del día, tanto de la orilla de la laguna como del mar. Se hizo el reconocimiento visual de las características morfológicas de la deposición fecal como color, volumen y tipo. Las muestras se colocaron en tubos viales estériles con un medio de transporte enriquecido en frío a $4{ }^{\circ} \mathrm{C}$.

Las muestras fueron agrupadas por especies y días de recolección, combinando 10 muestras para obtener al final $5 \mathrm{ml}$ por combinación. Este material fue centrifugado y luego filtrado. El aislamiento del APMV-1 se 
hizo en huevos embrionados libres de patógenos específicos (SPF) de 10 días de edad, por inoculación de la muestra en la cavidad alantoidea. Los embriones fueron incubados a $37^{\circ} \mathrm{C}$ por 5 días, evaluándose diariamente su viabilidad. Los embriones muertos se guardaron en refrigeración $\left(4^{\circ} \mathrm{C}\right)$. Los embriones que sobrevivieron al $5^{\circ}$ día fueron sacrificados por medio de refrigeración. Se colectó el fluido alantoideo para evaluar su actividad hemaglutinante por medio de la prueba de hemoaglutinación.

Se consideró que el hallazgo de una o más muestras era indicativo de que la presencia del virus se encontraba en una prevalencia de por lo menos $1 \%$.

La prevalencia se expresó con intervalos de confianza del 95\%, empleando una simulación beta implementada en una planilla electrónica Excel XP (Microsoft Corp). Para la simulación se empleó el programa @Risk (Palisade Corp) con 3000 interacciones.

En el Cuadro 1 se señala la distribución de muestras según la familia de las especies muestreadas. Todas las muestras analizadas fueron negativas al aislamiento viral. Los resultados de prevalencia estimados por medio de la simulación beta indicó una prevalencia media de $0.1 \%$ con una distribución entre 0.002 y $0.4 \%$. Esta es una prevalencia muy baja para considerar a las aves silvestres estudiadas, como posible fuente de infección hacia las aves domésticas. Similares resultados fueron encontrados en el país (Chang, 1998, Shimabukuro, 2000) y en otras regiones como Australia con aves silvestres Psitácidas y palomas (Garnett, 1989), en EE.UU. con diversas especies de aves silvestres y semidomésticas (Alfonso et al., 1995; Pearson et al., 1995; Graves, 1996), y en Filipinas (Jonson, 1986) con aves psitácidas nativas y exóticas. No obstante, en Canadá y el norte de los EE.UU. ocurrieron brotes que afectaron a cormoranes y pelícanos en 1990 y 1992 (Glaser et al., 1999) y, además, en pavos se pudo aislar un virus indistinguible por batería de MABs; pero, en
Cuadro 1. Distribución de muestras de heces por familia de aves silvestres

\begin{tabular}{lcc}
\hline Familia & $\begin{array}{c}\text { Muestras } \\
\text { (n) }\end{array}$ & $\begin{array}{c}\text { Pools } \\
\text { (n) }\end{array}$ \\
\hline Anatidae & 40 & 5 \\
Ardeidae & 73 & 8 \\
Haematopodidae & 171 & 18 \\
Laridae & 181 & 19 \\
Rynchopidae & 60 & 6 \\
Scolopacidae & 130 & 14 \\
Rallidae & 19 & 3 \\
Pelecanidae & 50 & 5 \\
Phalacrocoracidae & 176 & 16 \\
\hline \multicolumn{1}{c}{ Total } & 900 & 94 \\
\hline
\end{tabular}

esencia, genéticamente igual al de los cormoranes (King, 1999).

Dado que las formas velogénicas viscerotrópicas de la enfermedad de Newcastle en el Perú se vienen observando de una manera continua desde 1994 en aves de postura comercial, de riña, traspatio y con menor frecuencia en pollos de engorde, se había asumido que las aves silvestres podrían ser importantes reservorios de la enfermedad; sin embargo, resultados de observaciones hechas por el grupo de investigadores, incluyendo el presente trabajo, viene demostrando que los reservorios de la enfermedad de Newcastle, estarían probablemente en otro tipo de aves, tales como las aves de traspatio o de riña.

\section{Literatura Citada}

\section{Alfonso CP, Cowen BS, Van Campen} H. 1995. Influenza A viruses isolated from waterfowl in two wildlife management areas of Pennsylvania. J Wildlife Dis 31: 179-185. 
2. Chang P. 1998. Detección de la prevalencia de anticuerpos contra el virus de la Enfermedad de Newcastle en aves silvestres paseriformes y columbiformes en la provincia de Chancay. Tesis de Médico Veterinario. Lima: Facultad de Medicina Veterinaria, Universidad Nacional Mayor de San Marcos. 33 p.

3. Ferrer R. 2002. Prevalencia de anticuerpos al virus de la Enfermedad de Newcastle en aves domésticas Gallus gallus del departamento de Lima en el año 2001. Estudio caso-control. Tesis de Médico Veterinario. Lima: Facultad de Medicina Veterinaria, Universidad Nacional Mayor de San Marcos. $46 \mathrm{p}$.

4. Garnett ST. 1989. Survey for Newcastle disease virus in northern Queensland birds. Aust Vet J 66: 129-134.

5. Glaser LC, Barker IK, Weseloh DV, Ludwig J, Windingstad RM, Key DW, Bollinger TK. 1999. The 1992 epizootic of Newcastle disease in double-crested cormorants in North America. J Wildlife Dis 35: 319-330.

6. Graves IL. 1996. Newcastle disease viruses in birds in the Atlantic flyway. Vet Res 27: 209-218.

7. Icochea D. 2007. Relación entre aves silvestres y la Enfermedad de Newcastle en el Perú. Tesis de Magíster. Lima: Facultad de Medicina Veterinaria, Universidad Nacional Mayor de San Marcos. $71 \mathrm{p}$.

8. Jonson DC. 1986. Failure to demonstrate Viscerotropic Velogenic Newcastle disease in Psittacine birds in the Republic of Philipines. Avian Dis 30: 813-815.

9. Jordan FT. 1990. Paramyxoviridae (Newcastle disease and others). In: Poultry diseases. $3^{\text {rd }}$ ed. London: Bailliere Tendal. p 121-136.

10. King D. 1999. Enfermedad de Newcastle. En: XVI Congreso Latinoamericano de Avicultura. Lima. p 56-62.

11. Pearson GL, Mc Cann MK. 1975. The role of indigenous wild semidomestic, and exotic birds in the epizootiology of Velogenic Viscerotropic Newcastle Disease in southern California. JAVMA. 167: 610-614.

12. Shimabukuro C. 2000. Determinación de anticuerpos contra el Virus de la Enfermedad de Newcastle en Psitácidas en cautiverio en el Parque de las Leyendas. Tesis de Médico Veterinario. Lima: Facultad de Medicina Veterinaria, Universidad Nacional Mayor de San Marcos. $24 \mathrm{p}$. 